\title{
BIM AND VISUAL PROGRAMMING LANGUAGE SUPPORTING PROJECT CONSTRUCTABILITY
}

\author{
Yan Mota Veras de Carvalhoํㅡ, Luiz Carlos Magalhães Olimpio², Matheus Gomes \\ Lima $^{3}$, Mariana Monteiro Xavier Lima ${ }^{4}$, and José de Paula Barros Neto ${ }^{5}$
}

\begin{abstract}
Construction projects need to consider the multiplicity of constructive aspects on its development process via predefined parameters. Constructability is a concept that comprehends these features, and has a direct relationship with time, cost, and quality criteria. However, it is often neglected due the difficulty in measuring its indicators during project design process. Additionally, the indicators measurement is usually laborious, resulting in waste of resources during design stage. Recognizing this scenario, this research proposes a practical tool for designers and integrated with a design software. One of the steps of the model is the identification of project performance indicator's regarding its constructability. Following is the development of a programmable routine, created on Dynamo, used for the data collection from the BIM model. The indicators are updated in real time, granting project constructability evaluation during the modelling process. The alghorithm developed allows users to propose solutions that are almost impossible when using only a modeling software and that would require many operations. Some limitations that were identified are: the developed routines may not support unforeseen variations and since the model was built with a visual programming tool (Dynamo), it may have to undergo some adaptations for correct efficiency in other tools.
\end{abstract}

\section{KEYWORDS}

Constructability, visual programming, product development, lean construction.

\section{INTRODUCTION}

The design and execution processes in the construction industry are complex and fragmented (Vrijhoef and Koskela 2005). These two main disciplines are isolated in the traditional construction (Zhang et al. 2016). As a result, the designer makes decisions that

1 Lean Consultant of Capital Projects and Infrastructure, VerumPartners, Fortaleza, Brazil, +55 88 99660-3141, yanveras00@ gmail.com, orcid.org/0000-0002-6038-4056

2 Engineering Analyst - Lean Planner, Cortez Engenharia Ltda., Fortaleza, Brazil, +55 85 98638-7670, olimpio@alu.ufc.br, orcid.org/0000-0003-3576-0547

3 Master's Student, Federal University of Ceará (UFC), Fortaleza, Brazil, +55 88 99765-0743, matheusgsdelima@alu.ufc.br, orcid.org/0000-0002-6243-6075

4 Adjunct Professor, Department of Architecture and Urbanism and Design, Federal University of Ceará (UFC), Fortaleza, Brazil, mariana@ daud.ufc.br, orcid.org/0000-0002-6560-4070

5 DBA., Full Professor, Department of Structural Engineering and Civil Construction, Federal University of Ceará (UFC), Fortaleza, Brazil, +55 85 99969-1871, barrosneto@gercon.ufc.br. orcid.org/0000-0001-5131-4593 
directly impact on variables not previously covered, such as constructability, durability and client suitability whose consequences are suboptimal solutions and a great number of design and construction rework. (Alarcón and Mardones 1998).

Furthermore, the consideration of the constructive aspects in the design stage delivers significant benefits to cost, time, quality and safety in the quality of the construction process. In this context, emerges the importance of indicators. They are quantifiable representation of these aspects, giving support to the decision-making (Lantelme, 1994).

There are proposals and recommendations to quantify the efficiency of the design stage (Mascaro, 1985). However, evaluating projects in a quantitative way requires effort and time. The construction project simulation in a virtual environment by the combination of Building Information Modeling (BIM) and constructability concepts contributes to accomplish objectives in terms of time, cost and quality (Nascimento et al. 2017).

The use of BIM in the design process facilitates the development of automated verification of real-time model information and trade-offs can be more easily assessed, such as energy, functionality, aesthetics, and constructability through a fast and reliable process of using parameters and spatial relations between elements (Zhang et al. 2016). In this way, it is possible to predict the performance of the construction and assist decision making in the design phase. These processes can be transformed into programmable routines, allowing the evaluation of alternatives and project indicators (Nembrini, Samberger and Labelle, 2014). Currently, computational advancements, both at software and hardware levels, have enabled access to tools that automate the collection and processing of data for design evaluation (Lima, 2016).

Visual Programming Languages (VPL) are formal languages, based on images, defined by graphic objects consisting of nodes and connections (Singer and Borrmann, 2015). The VPLs are easily interpreted and understood because they comprise a visual logical arrangement, without the need of advanced knowledge in a given textual language. In the context of BIM, VPLs have become progressively important in dealing with geometric modelling processes (Kensek, 2015), thus, automating the information collection of a BIM model and the calculation of these indicators.

In the search for understanding constructive factors on contruction, organizations and scholars have discussed its concept. For CIRIA (1983) the constructability would be the dimension in which the design of a building supports the facility of construction, considering requirements of the concluded building. The meaning involves the integration of knowledge and constructive experience during the conception, planning, design and execution phases of the construction, aiming at simplifying the constructive operations through the awareness of the constructive technology to be adopted in the project (Mydin et al., 2011).

The goal of constructability is to improve the efficiency of construction processes by developing designs that consider execution aspects (Hon, Gairns, and Wilson, 1988). It benefits the cost, productivity and quality of the work (Dantas Filho, Angelim, Guedes, Silveira and Barros Neto, 2016). This is achieved by the increase of productivity, reduction of rework, intensive work, and satisfaction of stakeholders hence the constructive rationalization by improving construction process (Anquino and Melhado, 2002).

This procedure can be done by changing attributes in any of the designs, as in a structural design, for instance, which can promote a layout solution that results in less congestion in execution with higher tolerances and lower armour densities (Mydin et al., 2011). The degree of project simplification; the extent of the standardization adopted in 
the company; the executive sequence and interdependence between activities; accessibility to workspaces; and communication between project and work are some factors that can influence the constructability (Oliveira, Lantelme and Formoso, 1995).

Performance measurement systems are especially important in the construction industry (Bassioni., 2004). The first step starts with the selection of indicators. Indicators may have the role of clarify the performance of an organization, act in the control of a process, set goals, and act on motivating workers (Folan and Browne, 2005). Indicators are widely used in the measurement construction productivity, which is directly related to the constructive aspects of the projects. Being design-based, it is appropriate that the measurement of construction performance be concentrated in the design performances (Pekuri et al., 2011).

Spatial information is required for constructability analysis, where complex computations are obtained with the use of easily extracted data from the BIM model (Khemlani, 2004). Therefore, the BIM model facilitates design tests and activity sequencing to achieve better constructability (Zhang et al., 2016). However, the BIM design tools currently available do not provide model verifications tools. To solve this problem, an application can be developed ont this plataform, providing ease for a designer to validate this model according to the target rules (Zhang et al., 2013).

Model checkers based on automated rules include Revit, Navisworks, Solibri Model Checker (SMC), Express Data Manager (EDM) and FORNAX (Uhm et al., 2015). In these approaches the rules are implemented by software developers as procedural code embedded in the building code verification system (Eastman et al., 2009). The development of checking systems based on VPL is an approach that is being frequently used. Myers (1990), based on a survey of 50 visual programming languages, showed that a more visual style of programming can be easier to understand for non-programmers or novice programmers (Architects and Engineers normally fit into these categories).

In the context of BIM, VPLs have become progressively important to deal with geometric modeling processes, and several authors have researched the use of some type of VPL at some stage of their rule checking process. Ji and Leite (2018) applied VPL for checking crane plans and updating models. Khan et al. (2019) proposed a set of rule based alghoritms to asses excavation safety and generate protections. Ghannad et al (2019) uses VPL to propose a modularized structure for check BIM models compliance. Preidel and Borrmann (2016) introduce the Visual Code Checking Language (VCCL), which uses a graphical notation in order to represent the rules of a code.

This research proposes a tool that uses Visual Programming Language to create routines that extract data to calculate constructability metrics and evaluate building projects before the execution phase.

\section{METHODOLOGY}

The development of the project's constructability assessment tool was performed in five stages, presented in Figure 1. The first two stages of the model, that consists in the problem state and the literature review was presented in the introduction of this paper. The next three stages are described in the next sections.

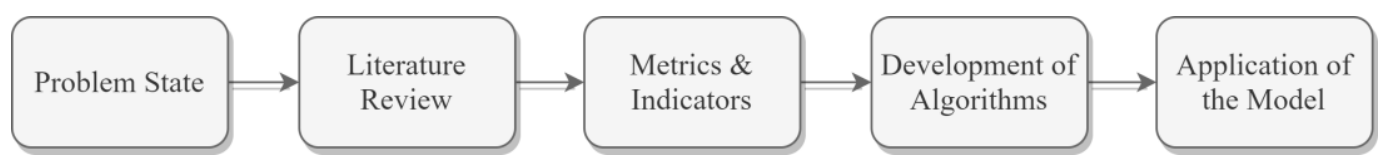

Figure 1: Model Stages 


\section{METRICS AND INDICATORS}

Starting from a broad search in the literature, a group of indicators which show relation with the principles of constructability were selected. The set of metrics represents the standardization of the project, the simplification of the parties, the interdependence between activities, and ease of access. As the indicators meet more than one of these principles, the categorization was performed by the system they comprise. The next step was the filtering processes, which take into account the projects' capability to use quantitative data that can be automated with the information available and its geometric elements information.

\section{DeVElopMent OF Algorithm}

A frame that allowed the automation of calculations using the model data was developed with the Autodesk ${ }^{\circledR}$ Revit (2020) and its interface with Dynamo (2.3). The choice of Autodesk $®$ Revit was based on the researchers' familiarity and due Dynamo is the most frequent solution for this software. Next, a parametric approach analysis was established. That was done by prioritizing the evaluation of the parameters and information present in the elements of the model.

This approach leaded to a wider analysis since it demands lower computational cost. In order to make the calculation script as simple as possible, its main tasks were to read the model to collect data, then manipulate and use it to calculate the metrics and a compilation process into a worksheet, where the results were graphically displayed.

The final algorithm was implemented in the Dynamo Player, an interface within the Revit that allows the use of scripts without requiring VPL knowledge. This makes the proposed tool accessible to all types of users. It also allows calculations to be performed iteratively with user modifications, which can instantly assess the impact of changes.

\section{APPLICATION OF THE MODEL}

The projects that were analyzed have different geometric characteristics, and necessary information for the calculation of the indicators in key families and elements, justifying its selection. The first project (Figure 2) was a residential high standard building of a single tower with two garage floors, 15 typical floors and 1 roof. It has three apartments per floor, with approximately $90 \mathrm{~m}^{2}$ each. The second project analyzed (Figure 3) had two towers with 22 floors each and 4 apartments per floor. Only one of the towers was selected, having apartments with $95 \mathrm{~m}^{2}$.

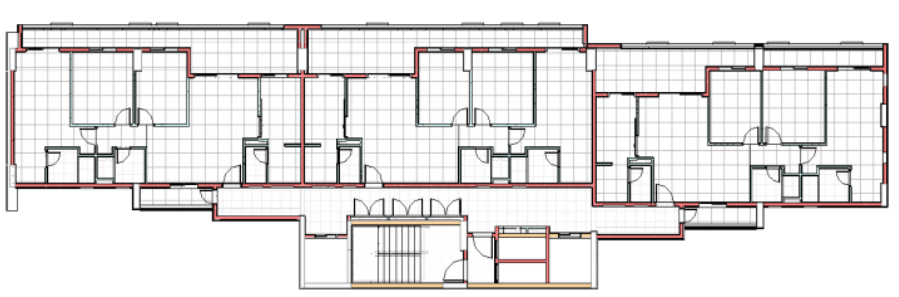

Figure 2: Project 1 Floor Plant

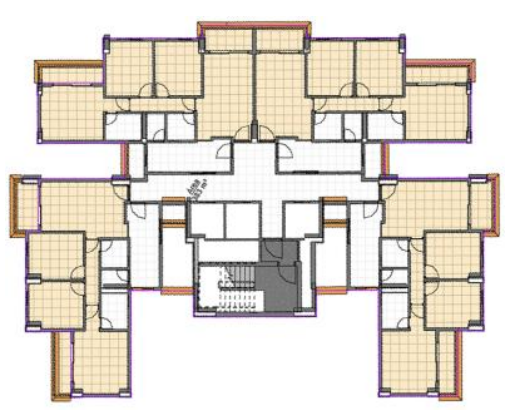

Figure 3: Project 2 Floor Plant 


\section{RESULTS}

\section{METRICS}

The selection of metrics resulted in 11 items that support the measurement of the constructability of the project. These are presented in Table 1.

Table 1: Selected Constructability Metrics

\begin{tabular}{|c|c|c|c|c|}
\hline & Name/Reference & Equati & & Description \\
\hline \multicolumn{5}{|c|}{ ARCHITECTURAL } \\
\hline 1 & $\begin{array}{l}\text { Compactness Index } \\
\text { Lantelme (1994) } \\
\text { Mascaró (2010) }\end{array}$ & $C I=2 * \frac{\sqrt{\pi * \text { Farea }}}{F p}$ & $\begin{array}{l}\text { Farea:floor area } \\
\text { Fp: floor perimeter }\end{array}$ & $\begin{array}{l}\text { It represents the inverse relation of the geometric } \\
\text { complexity of the perimeter of the pavement. The further } \\
\text { from a square (0.84), the lower the index, and the lower } \\
\text { the constructability }\end{array}$ \\
\hline 2 & $\begin{array}{l}\text { Wet Area Index } \\
\text { Oliveira, Lantelme } \\
\text { and Formoso (1995) } \\
\text { Narloch (2015) }\end{array}$ & $W A I=W a / F a r e a$ & Wa:wet Area & $\begin{array}{l}\text { Wet areas require more services due to waterproofing, } \\
\text { testing and use of ceramics in masonry. }\end{array}$ \\
\hline 3 & $\begin{array}{c}\text { Wall Density } \\
\text { Oliveira, Lantelme } \\
\text { and Formoso (1995) }\end{array}$ & $W D=$ Farea $/$ Wha & $\begin{array}{l}\text { Wha: wall } \\
\text { horizontal projection } \\
\quad \text { area }\end{array}$ & $\begin{array}{l}\text { The purpose of this metric is to verify the degree of } \\
\text { optimization of the floor subdivisions }\end{array}$ \\
\hline 4 & $\begin{array}{l}\text { Facade Index } \\
\text { Oliveira, Lantelme } \\
\text { and Formoso (1995) } \\
\text { Narloch (2015) }\end{array}$ & $F I=$ Farea $/$ Fcarea & $\begin{array}{l}\text { Fcarea: Facade } \\
\text { area of the typical } \\
\text { floor }\end{array}$ & $\begin{array}{l}\text { The vertical planes of the facades are more difficult and } \\
\text { expensive to build. The indicator reveals the proportion of } \\
\text { facades in relation to the typical floor plane of the } \\
\text { building. }\end{array}$ \\
\hline 5 & $\begin{array}{l}\text { Frame Density } \\
\text { Oliveira, Lantelme e } \\
\text { Formoso (1995) }\end{array}$ & $D E=$ Farea $/$ Wvarea & $\begin{array}{l}\text { Wvarea: vertical } \\
\quad \text { walls area } \\
\text { Farea: Frames area } \\
\text { (doors and windows) }\end{array}$ & $\begin{array}{l}\text { Windows and doors frames require more services and } \\
\text { increase constructive complexity }\end{array}$ \\
\hline 6 & $\begin{array}{l}\text { Frame Standard Index } \\
\text { Oliveira, Lantelme e } \\
\text { Formoso (1995) }\end{array}$ & $F S=D f r / F r q$ & $\begin{array}{l}\text { Dfr: Dissimilar } \\
\quad \text { frames } \\
\text { Frq: Frames } \\
\quad \text { quantity }\end{array}$ & $\begin{array}{c}\text { The greater diversity of frames affects the complexity of } \\
\text { the project, the purchase, the planning and the execution } \\
\text { operation. }\end{array}$ \\
\hline \multicolumn{5}{|c|}{ STRUCTURAL } \\
\hline 7 & $\begin{array}{l}\text { Columns Density } \\
\text { Index } \\
\text { Jarkas (2010) }\end{array}$ & $C D i=C p a / C q$ & $\begin{array}{l}\text { CPa: Columns } \\
\text { Projection Area } \\
\text { CAQ: Columns } \\
\text { Adjusted Quantity }\end{array}$ & $\begin{array}{l}\text { Columns restrict movement in the worksite and increase } \\
\text { foundation distribution. }\end{array}$ \\
\hline 8 & $\begin{array}{l}\text { Beams Density Index } \\
\text { Jarkas (2010) }\end{array}$ & $\begin{array}{c}\text { Se } B l / \text { Farea } \leq 0.45(1) \text { if } \\
\text { not }(2) \\
(1) B D i=B l /(0.45 * \\
\text { Farea) or } \\
\text { (2) } B D i=2-B l /(0.45 * \\
\text { Farea })\end{array}$ & $\begin{array}{l}\text { Bl: Beams Length } \\
\text { Farea: Floor Area }\end{array}$ & $\begin{array}{l}\text { This metric represents the efficiency of the project. The } \\
\text { lower this value, the smaller the complexity of shapes and } \\
\text { concreting services, also reducing interferences. }\end{array}$ \\
\hline 9 & $\begin{array}{l}\text { Columns Standard } \\
\text { Index } \\
\text { Jarkas (2010) }\end{array}$ & $C S i=D C / C Q$ & $\begin{array}{l}\text { DC: Dissimilar } \\
\text { Columns } \\
\text { CQ: Columns } \\
\text { Quantity }\end{array}$ & $\begin{array}{l}\text { This metric considers the complexity in the individuality } \\
\text { of structural types, through the ratio of different pillars in } \\
\text { their cross sections and the total number of pillars. }\end{array}$ \\
\hline 10 & $\begin{array}{l}\text { Beams Standard Index } \\
\text { Jarkas (2010) }\end{array}$ & $B S i=D B / B Q$ & $\begin{array}{c}\text { DB: Dissimilar } \\
\text { Beams } \\
\text { BQ: Beams Quantity }\end{array}$ & $\begin{array}{l}\text { This metric measures the complexity in the individuality } \\
\text { of structural types, through the ratio of quantities of } \\
\text { different beams in their cross sections and the total } \\
\text { number of beams. }\end{array}$ \\
\hline 11 & $\begin{array}{l}\text { Floor Standard Index } \\
\text { Jarkas (2010) }\end{array}$ & $F S i=\frac{D F}{F Q}$ & $\begin{array}{c}\text { DF: Dissimilar } \\
\text { Floors } \\
\text { FQ: Floors Quantity }\end{array}$ & $\begin{array}{l}\text { This metric calculates the complexity in the individuality } \\
\text { of structural types, through the relation of quantities of } \\
\text { different slabs in their cross sections and the total number } \\
\text { of slabs. }\end{array}$ \\
\hline
\end{tabular}




\section{SCRIPT STRATEgIES}

The structure developed results into a set of scripts (Figure 2), described next:

- Parameter collection routine: The node "Categories" is used to select the category of interest, and it feeds the node "All Elements of Category" that collects all the elements of the chosen category. It then source the "GetParameterValueByName" node which also needs the textual specification of the parameter to return a list of its values. This routine collects instance parameters, and if necessary it collects type parameters by the "ElementType" node applied first.

- Filter script: From the filtered list, it connects to a check node that returns a list of Booleans, along with the filtered list that feeds the "List.FilterByBoolMask" node which returns two new lists, one for the true and the other for the false tests.

- Sum and Count Script: The "Math.Sum" node receives a list of values and returns the cumulative sum. The "List.Count" node counts the number of values in a list.

- Conditional Script: The "If" node allows testing by condition, it needs to be fed with a test containing a boolean and the answers for a true and false function.

- Calculation Script: the implementation of specific equations through the "Code Block" node. It was used to calculate the indexes fed by the selected parameters.

- Export Script: The indexes values feeds the "List Create" node that binds them to a list, which is connected to the "Data.ExportExcel" node. To write the list to an Excel spreadsheet, it is necessary to supply the node with a row and column number, the name of the worksheet, the path of the file on the system, and a Boolean to allow the data to be overwritten. The program also allows to export via .csv file, implemented in the script.

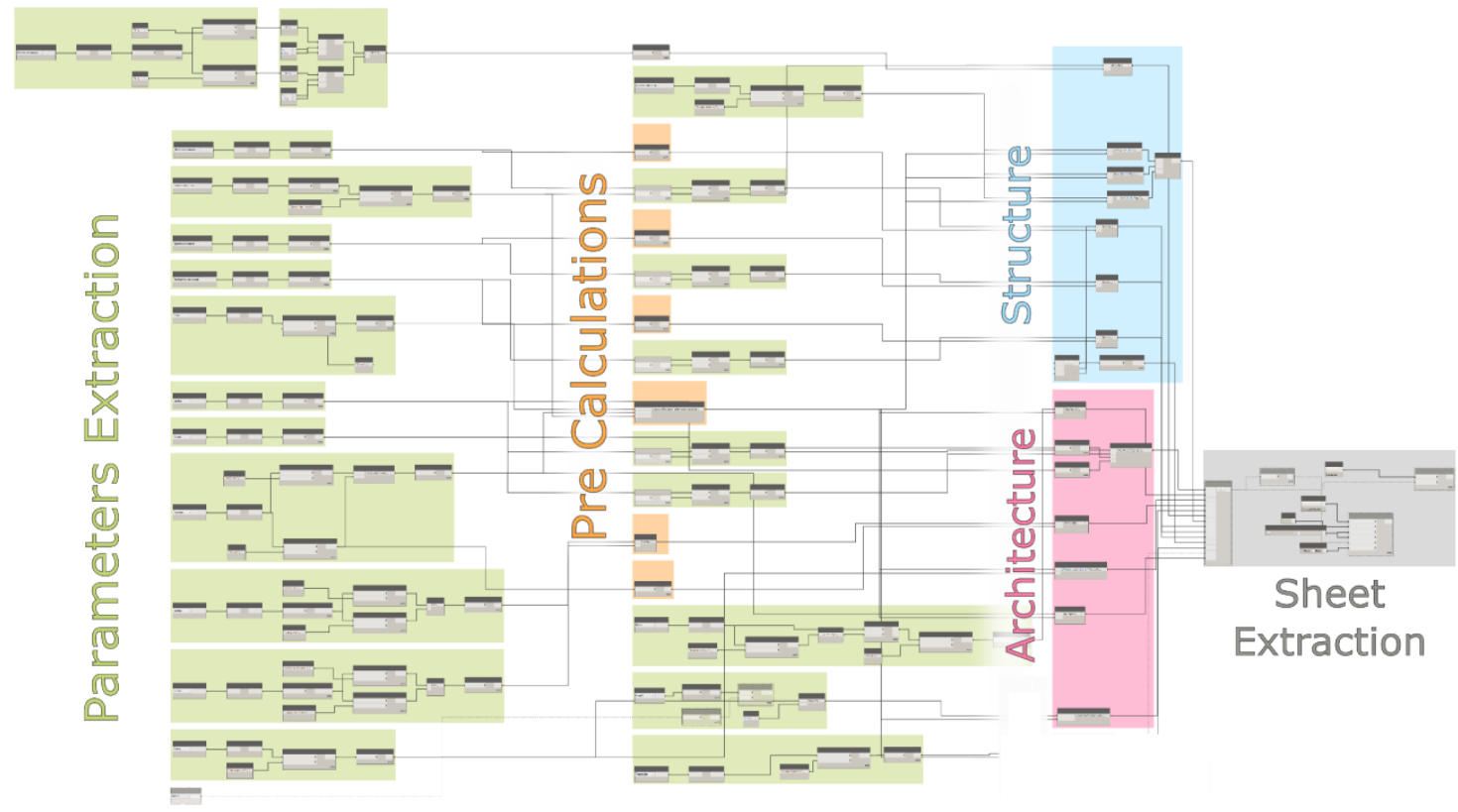

Figure 4: Scripts on Dynamo 


\section{APPLiCATION}

The application of the script presented in Figure 2 in the two projects resulted in the values of the constructability indexes found in Table 2. This table shows the direction in which the optimization takes place in the column named optimization. Then, when the arrow points upwards, it indicates that the higher the indicator for the project, the closer to the ideal this characteristic is. While when pointing downwards, it is closer to the ideal when the value is lower. Although the two projects present similar characteristics like the area, general dimensions and quality standard, the structural and architectural solutions are very particular, which could generate different constructability indicators.

By analyzing the solutions adopted in the design and the calculated metrics, it was possible to evaluate if the results match coherently with the logic of the equations proposed by authors in Table 1 . Thus, the functionality of the script and its practicality was verified through automating the collection of information and calculations.

Starting from the first indicator, it was apparent that the first project Compactness Index, despite having a rectangular shape, has a higher value than the second project. This is because the second project has several recesses, obtaining a large perimeter. As presented by Mascaró (2010) both projects are far from the optimal value (0.84) that represents the shape of a square. This may adversely impact the cost and constructability of both projects, but factors such as constructive methods and builder experience should be taken into account.

The index of facades is related to compactness, and comprises the area of external walls on floor area. Thus, the first project has a proportionally smaller perimeter than the second, in turn, has more compartments, increasing the density of vertical planes. Both of these pieces of information were confirmed by a visual analysis of the models.

The wet area index of the first project was higher than the second. This is only due to the greater proportion of balconies in project 1 . This index relates to the wet area, which implies services such as waterproofing, wich confered less constructability to project 1.

The indexes related to frames showed very different results. Project 1 has more frames per wall area, which decreases the constructability, but its frames vary less, which increases the constructability, compared to project 2 . Therefore, the first project is better suited to the principle of standardization of design, while the second is better at simplifying the parts.

The structure indicators presented a considerable difference between the projects. Project 2 presented symmetry in the vertical direction and the structural solution adopted is more compact than that of project 1 , which has no symmetry. In addition, the typology of the slabs of the projects were different: in the first, solid, and ribbed slabs in the second.

Considering the Structure, Project 2 presented good results in the Standard Indexes by having greater symmetry, reducing variations in the sections of the structural elements. The Density Indexes showed that the columns present less dissimilar values than the beams; this is due to the similarity of vertical loading. Project 1 has larger spans, adopting pre-stressed beams, which affected their structural indexes negatively. During the project design phase of Project 2, it could be assumed that the structure constructability was considered more important, while in Project 1 the shape of the building was more influential. 
Table 2: Tool application results

\begin{tabular}{ccccccc}
\hline $\mathbf{N}$ & Index & Optimization & Project 1 & Project 2 & Difference & $\%$ \\
\hline & & \multicolumn{7}{c}{ Architecture } & & & \\
\hline 1 & Compactness & $\uparrow$ & 0,55 & 0,51 & 0,05 & $8,4 \%$ \\
2 & Wet Area & $\uparrow$ & 0,22 & 0,14 & 0,08 & $36,8 \%$ \\
3 & Wall Density & $\downarrow$ & 0,10 & 0,12 & $-0,01$ & $-14,3 \%$ \\
4 & Facade Indicator & $\downarrow$ & 1,02 & 1,10 & $-0,08$ & $-8,1 \%$ \\
5 & Frame Density & $\downarrow$ & 0,20 & 0,15 & 0,05 & $25,8 \%$ \\
6 & Frame Standard & $\uparrow$ & 0,26 & 0,18 & 0,09 & $33,3 \%$ \\
\hline \multicolumn{7}{c}{ Structure } \\
\hline 7 & Columns Density & $\downarrow$ & 0,30 & 0,23 & 0,07 & $23,0 \%$ \\
8 & Beams Density & $\downarrow$ & 0,83 & 0,54 & 0,29 & $35,2 \%$ \\
9 & Columns Standard & $\downarrow$ & 0,65 & 0,27 & 0,37 & $57,9 \%$ \\
10 & Beams Standard & $\downarrow$ & 0,29 & 0,13 & 0,16 & $55,5 \%$ \\
11 & Floor Standard & $\downarrow$ & 0,29 & 0,15 & 0,14 & $47,5 \%$ \\
\hline
\end{tabular}

\section{CONCLUSION}

As presented during the proposition, the collection and calculation procedures were performed with low effort, in a short period of time and the programming of the routine occurred in a fluid and fast way, proving the smoothness in its development. This feature allows users to propose solutions that are almost impossible when using only a modeling software and that would require many operations, without the ability to automate such processes. The interface warns of errors in the script, easing its construction, and promoting reliability to the execution.

It is verified that the designers must create the models considering the information necessary for the collection of data, following the standard to be adopted by the script. As an example, the area of wet floor was collected from the parameter of the floor with waterproofing, thus, for the extraction the models must have this information available in this parameter. It is recommended that designers promote the standardization of information allocation in models. Improving the programming, it is possible to develop flexible routines, with intelligent structures that identify in which parameters the desired information was allocated.

For this study, 11 indicators were chosen in scientific researches. These indicators have a relation with constructive aspects, in which the control of them should contribute to the improvement of the construction performance. However, the effects of the project constructability on the construction depend on several variables. It is advised that the designer should use a performance system incorporating this indicator, and promote the monitoring of the effects considering the criteria of the construction company, ensuring reliable results that take into account the specificities of the scenario. If properly validated, the construction company can create its own indicators that could be implemented in a script.

The proposal is shown as an easy-to-use tool for measuring indicators dynamically, assisting designers in project decisions due to the instant updating of values. The adoption of the tool in the construction should promote a necessary approximation between aspects of design and construction, reducing the communication deficiencies of these two disciplines, which generate executions with lower performances in terms of cost, time, quality and rework.

Some limitations were identified during the research. It is noteworthy the fact that the developed routines are governed by the initial definitions, and may not support unforeseen variations. The model was tested with a visual programming tool (Dynamo), 
and may have to undergo some adaptations for correct efficiency in other tools. Another difficulty is the need to use modeling standards to guarantee conformity in the model data. The possible use of a standardized library, with an object classification system, could be used to overcome this barrier.

Notwithstanding the low control in the literature review, the indicators have practical support and are directly related to the constructability. Additionally, the papers selected from which the indicators were extracted are from researchers with multiple studies applied in the respective area of their indicators. Although, is recognized a possibility of improving and expanding the research to meet other indicators, as well as proposing a general indicator comprising key indicators.

As a future research, it is suggested to measure the effects of the script application during a project, collecting information from the design and construction stages, electrical and plumbing data and understand how its implementation influences the design process.

\section{REFERENCES}

Alarcon, L. F. and Mardones, D. A. (1998). "Improving the design-construction interface.' 6th Annual Conference of the International Group for Lean Construction, Guarujá, Brazil, http://www.iglc.net/papers/details/34.

Anquino, J. P. R. and Melhado, S. B. (2002). "The importance of the design for production in the design process management in building construction." 10th Annual Conference of the International Group for Lean Construction, C. T. Formoso and G. Ballard, eds., Gramado, Brazil, http://www.iglc.net/papers/details/170.

Bassioni, H. A., Price, A. D., and Hassan, T. M. (2004). "Performance measurement in construction." Journal of management in engineering, 20(2), 42-50.

Cândido, L. F., Lima, S. H. O., and Barros Neto, J. P. (2016). "Analysis of performance measurement systems in the construction industry" Ambiente Construído, 16(2), 189208.

Dantas Filho, J. B. P., Angelim, B. M., Guedes, J. P., Silveira, S. S., and Barros Neto, J. P. (2016). "Constructability analysis of architecture-structure interface based on bim." 24th Annual Conference of the International Group for Lean Construction, Boston, Massachusetts, USA, http://www.iglc.net/papers/details/1273.

Eastman, C., min Lee, J., suk Jeong, Y., and kook Lee, J. (2009). “Automatic rule-based checking of building designs."Automation in Construction, 18(8), 1011-1033.

Folan, P. and Browne, J. (2005). "A review of performance measurement: Towards performance management." Computers in industry, 56(7), 663-680.

Ghannad, P., Lee, Y.-C., Dimyadi, J., and Solihin, W. (2019). "Automated bim data validation integrating open-standard schema with visual programming language."Advanced Engineering Informatics, 40, 14-28

Jarkas, A. M. (2010). "Buildability factors affecting formwork labour productivity of building floors." Canadian Journal of Civil Engineering, 37(10), 1383-1394.

Kensek, K. (2015). "Visual programming for building information modeling: energy and shading analysis case studies." Journal of Green Building, 10(4), 28-43.

Khan, N., Ali, A. K., Skibniewski, M. J., Lee, D. Y., and Park, C. (2019). "Excavation safety modeling approach using bim and VPL."Advances in Civil Engineering, 2019.

Khemlani, L. (2004). "The ifc building model: A look under the hood." AECbytes feature, $1-10$. 
Lantelme, E. M. V. (1994). "Proposal for a system of quality and productivity indicators for civil construction." M.S. thesis, Universidade Federal do Rio Grande do Sul, Porto Alegre, Brazil, http://hdl.handle.net/10183/163597.

Lima, M. M. X. (2016). "Metamodel for multi-performance integration in architectural design." Ph.D. thesis, Universidade Estadual de Campinas, Campinas, Brazil, http://repositorio.unicamp.br/jspui/handle/REPOSIP/305374.

Mascaró, J. L. (1985). The cost of architectural decisions. Nobel São Paulo.

Mydin, S. H., Zin, R. M., Abd Majid, M. Z., Zahidi, M., and Memon, A. H. (2011). "Buildability attributes at design phase in malaysian building construction." International Journal of Sustainable Construction Engineering and Technology, 2(1).

Narloch, T. B. et al. (2015). "Constructibility indicator model from the geometric analysis of the project." M.S. thesis, Universidade Federal de Santa Catarina, Florianópolis, Brazil, https://repositorio.ufsc.br/xmlui/handle/123456789/156886.

Nembrini, J., Samberger, S., and Labelle, G. (2014). "Parametric scripting for early design performance simulation." Energy and Buildings, 68, 786-798.

Oliveira, M., Lantelme, E. M. V., and Formoso, C. T. (1995). "System of quality and productivity indicators for civil construction: User manual." SEBRAE/RS, Serviço de Apoio as Micro e Pequenas Empresas do Rio Grande do Sul. Porto Alegre.

Pekuri, A., Haapasalo, H., and Herrala, M. (2011). "Productivity and performance management managerial practices in the construction industry." International Journal of Performance Measurement, 1(1), 39-58.

Preidel, C., Daum, S., and Borrmann, A. (2017). "Data retrieval from building information models based on visual programming." Visualization in Engineering, 5(1), $1-14$.

Research, C. I. and Association, I. (1983). CIRIA special publication. CIRIA.

Singer, D., Borrmann, A., and Center, L. O. (2015). "A novel knowledge-based engineering approach for infrastructure design." The Fourth International Conference on Soft Computing Technology in Civil, Structural and Environmental Engineering, Prague, Czech Republic, Citeseer.

Solihin, W. (2004). "Lessons learned from experience of codechecking implementation". BuildingSMART Conference, Singapore, https://www.researchgate.net/publication/280599027_Lessons_learned_from_experi ence_of_code-checking_implementation_in_Singapore.

Uhm, M., Lee, G., Park, Y., Kim, S., Jung, J., and kook Lee, J. (2015). "Requirements for computational rule checking of requests for proposals (rfps) for building designs in south korea."Advanced Engineering Informatics, 29(3), 602-615.

Vrijhoef, R. and Koskela, L. (2005). "A critical review of construction as a project-based industry: identifying paths towards a project-independent approach to construction". Proceedings CIB Combining Forces. June, Helsinki. Forthcoming, 13-24.

Zhang, S., Teizer, J., Lee, J.-K., Eastman, C. M., and Venugopal, M. (2013). "Building information modeling (bim) and safety: Automatic safety checking of construction models and schedules."Automation in Construction, 29, 183-195.

Zhang, C., Zayed, T., Hijazi, W., Alkass, S., et al. (2016). "Quantitative assessment of building constructability using bim and $4 \mathrm{~d}$ simulation." Open journal of civil engineering, 6(03), 442. 